\title{
Tyrosine kinase domain mutations of EGFR gene in head and neck squamous cell carcinoma
}

\author{
This article was published in the following Dove Press journal: \\ OncoTargets and Therapy \\ 13 March 2017 \\ Number of times this article has been viewed
}

\author{
Chittibabu Vatte' \\ Ali M Al Amri² \\ Cyril Cyrus' \\ Shahanas Chathoth' \\ Sadananda Acharya ${ }^{3}$ \\ Tariq Mohammad Hashim ${ }^{4}$ \\ Zhara $\mathrm{Al} \mathrm{Ali}{ }^{2}$ \\ Saleh Tawfeeq Alshreadah ${ }^{2}$ \\ Ahmed Alsayyah ${ }^{4}$ \\ Amein $\mathrm{K} \mathrm{Al}-\mathrm{Ali}^{5}$ \\ 'Department of Genetic Research, \\ Institute for Research and Medical \\ Consultation, University of Dammam, \\ Dammam, ${ }^{2}$ Department of Internal \\ Medicine, King Fahd Hospital of the \\ University, University of Dammam, \\ Al-Khobar, ${ }^{3}$ Department of Stemcell \\ Research, Institute for Research and \\ Medical Consultation, ${ }^{4}$ Department \\ of Pathology, King Fahd Hospital \\ of the University, University of \\ Dammam, Al-Khobar, ${ }^{5}$ Department \\ of Biochemistry, College of Medicine, \\ University of Dammam, Dammam, \\ Kingdom of Saudi Arabia
}

Background: Epidermal growth factor receptor $(E G F R)$ is a commonly altered gene that is identified in various cancers, including head and neck squamous cell carcinoma (HNSCC). Therefore, EGFR is a promising molecular marker targeted by monoclonal antibodies and small molecule inhibitors targeting the tyrosine kinase (TK) domain.

Objective: The objective of this study was to investigate the spectrum of mutations in exons 18 , 19, 20, and 21 of the EGFR gene in HNSCC patients.

Materials and methods: This retrospective study included 47 confirmed HNSCC cases. Mutations in the TK domain, exons 18, 19, 20, and 21 of the EGFR gene, were detected by Scorpion ${ }^{\circledR}$ chemistry and ARMS ${ }^{\circledR}$ technologies on Rotor-Gene Q real-time polymerase chain reaction.

Results: The tumors exhibited EGFR-TK domain mutations in $57 \%$ of cases. Four cases of T790M mutations were reported for the first time among HNSCC patients. Out of the total mutations, L861Q (exon 21), exon 20 insertions and deletions of exon 19 accounted for the majority of mutations $(21 \%, 19 \%$, and $17 \%$, respectively). EGFR mutation status was correlated with the higher grade $(P=0.026)$ and advanced stage $(P=0.034)$ of HNSCC tumors.

Conclusion: Higher frequency of EGFR-TK domain mutations together with the presence of the T790M mutation suggests that identification of these mutations might streamline the therapy and provide a better prognosis in HNSCC cases.

Keywords: somatic mutations, insertions, deletions, T790M, therapy, real-time PCR

\section{Introduction}

Head and neck carcinoma represents one of the 10 most common cancers worldwide. ${ }^{1}$ More than $95 \%$ of head and neck cancers are squamous cell carcinoma (head and neck squamous cell carcinoma [HNSCC]), indicating that it is relatively a homogeneous disease. However, the wide spectrum of unexpected genetic aberrations that have been observed in recent genomic studies ${ }^{2,3}$ highlighted the molecular heterogeneity of the disease. Despite aggressive and diverse therapies, the survival rate of these patients has not markedly improved because of the frequent development of locoregional recurrences, distant metastases, and second primary tumors. ${ }^{4}$

Epidermal growth factor receptor (EGFR) protein overexpression is seen in $>80 \%$ of HNSCC cases ${ }^{5}$ and is associated with a poor prognosis. ${ }^{6}$ The overexpression of EGFR may apparently be triggered by numerous mechanisms such as epigenetic changes, gene amplification, and oncogenic viruses. ${ }^{7}$ Hypoxic tumor microenvironment increases the EGFR mRNA translation, thereby inducing EGFR overexpression. ${ }^{8}$ EGFR is a founding member of a HER (erbB) family, which consists of four closely related transmembrane receptors. ${ }^{9}$ EGFR has a single hydrophobic transmembrane domain, a cytoplasmic tyrosine kinase (TK)-containing domain, and an extracellular ligand-binding domain. ${ }^{10}$ The cascade on binding of a ligand to the latter domain initiates the EGFR
Correspondence: Chittibabu Vatte Department of Genetic Research, Institute for Research and Medical Consultation, University of Dammam, Al-Rakah, PO Box-1982, Dammam 3 I44 I, Kingdom of Saudi Arabia Tel +96633330867

Email cbvatte@uod.edu.sa (c)
hereby accept the Terms. Non-commercial uses of the work are permitted without any further permission from Dove Medical Press Limited, provided the work is properly attributed. For permission for commercial use of this work, please see paragraphs 4.2 and 5 of our Terms (https://www.dovepress.com/terms.php). 
oligomerization followed by autophosphorylation based on the activation of TK residue at $\mathrm{C}$ terminus. The phosphorylated tyrosine becomes a binding site for SH2 (Src homology 2) or PTB (phosphotyrosine Binding) domain-containing signaling molecules, including growth factor receptor-bound protein (GRB2) and phosphatidylinositol-3,4,5-triphosphate (PIP3). This initiates a cascade of downstream intracellular signal transduction pathways, namely, mitogen-activated protein kinase (MAPK), phosphatidylinositol-3-kinase (PIK3)AKT, and signal transducer and activator of transcription (STAT), ${ }^{11}$ which regulate cell proliferation, differentiation, invasion, angiogenesis, and metastasis. ${ }^{12}$ The EGFR gene is frequently overexpressed and mutated in human cancers, which is one of the driving forces behind the development of drugs to target the EGFR in general and TK in particular.

The TK domain mutations mostly occur between exons 18 and 21, which constitute single-base substitutions, insertions, and deletions. Alterations in exons 19 and 21 are most common in non-small cell lung carcinoma (NSCLC), which is the reason that this carcinoma responds to EGFR-tyrosine kinase inhibitors (TKIs). ${ }^{13,14}$ However, theoretically, most of the mutations in the TK domain result in conformational change, which regulates the sensitivity of TKI therapy. ${ }^{15}$

These hot spot mutations (exons 18-21) of the EGFR gene were mostly studied in NSCLC, and the mutation frequency was ethnically specific. ${ }^{16}$ Sparse data are available on EGFR-TK domain mutations in HNSCC globally and in the Saudi population. Previously, the PIK3CA mutation pattern in HNSCC patients of Saudi origin was studied, and a high frequency of PIK3CA mutations and five novel mutations were reported. ${ }^{17}$ The PI3K signaling molecules upon binding to the phosphorylated TK initiate a cascade of intracellular signal transduction pathways.

Therefore, the study of the prevalence of mutations in EGFR-TK in our population may be used as a predictive biomarker resulting in the provision of personalized treatment and shed some light on furthering the understanding of the genetic nature of the EGFR-TK domain. Molecular profiling of tumors, with a particular focus on genetic alterations, is essential to reduce the disease burden and increase the survival rate through improved therapies and more accurate prognosis. To explore the aforementioned hypothesis, the spectrum of mutations in exons 18-21 of the EGFR gene was investigated in $47 \mathrm{HNSCC}$ cases.

\section{Materials and methods}

\section{Tissue samples}

This retrospective study was conducted on a total of 47 formalin-fixed paraffin-embedded tissue samples from
HNSCC tumors from Saudi patients with HNSCC who attended from the King Fahd Hospital of the university. Of the 47 samples, 20 tumors were in the nasopharynx, 13 in the larynx, 4 in the hypopharynx, and 5 each in the oropharynx and the oral cavity. None of the patients underwent any pre-surgical intervention, including radiotherapy and/or chemotherapy. This study was approved by the Institutional Review Board of University of Dammam (\#IRB-2014-08044). All the participants in the research study gave written informed consent. Demographical and clinical parameter details were collected from the hospital records.

\section{Microdissection}

Each tumor tissue block with $>70 \%$ tumor content was cut into four $10 \mu \mathrm{m}$ sections using a microtome (SLEE Medical, Mainz, Germany).

\section{Genomic DNA isolation}

Genomic DNA was isolated by using QIAamp DNA FFPE tissue kit (Qiagen, Manchester, UK) as per the manufacturer's instructions.

\section{Quantification of DNA}

The concentration of the extracted DNA was determined by using Nanodrop spectrophotometer (Thermo Fisher Scientific, Waltham, MA, USA). The average DNA quantity observed was $95.1 \mathrm{ng} / \mu \mathrm{L}$ and the purity was 2.1 .

\section{Control assay}

As per the Therascreen ${ }^{\circledR}$ EGFR-Rotor-Gene Q (RGQ) polymerase chain reaction (PCR) kit (Qiagen, Hilden, Germany) mandate, the total amplifiable DNA for each sample was assessed on RGQ real-time PCR (Qiagen) using the control reaction mix. Control assay amplifies the exon 2 region of the EGFR gene. All the samples fulfilled the criteria of $\mathrm{C}_{\mathrm{T}}$ value between 23 and 30.69 in the green channel.

\section{Mutation assay}

The Therascreen EGFR RGQ PCR kit (Qiagen) detects a total of 29 (Figure 1) specific somatic mutations in exons 18-21 of the EGFR gene utilizing both $\mathrm{ARMS}^{\circledR}$ and Scorpion ${ }^{\circledR}$ technologies. Data analysis was performed by using Rotor gene proprietary software, and the mutation status was categorized qualitatively as positive and negative based on the Therascreen EGFR RGQ PCR kit guidelines.

\section{Statistical analysis}

The results were categorized as positive or negative for each mutation of the EGFR gene, and the Fisher exact test was used 


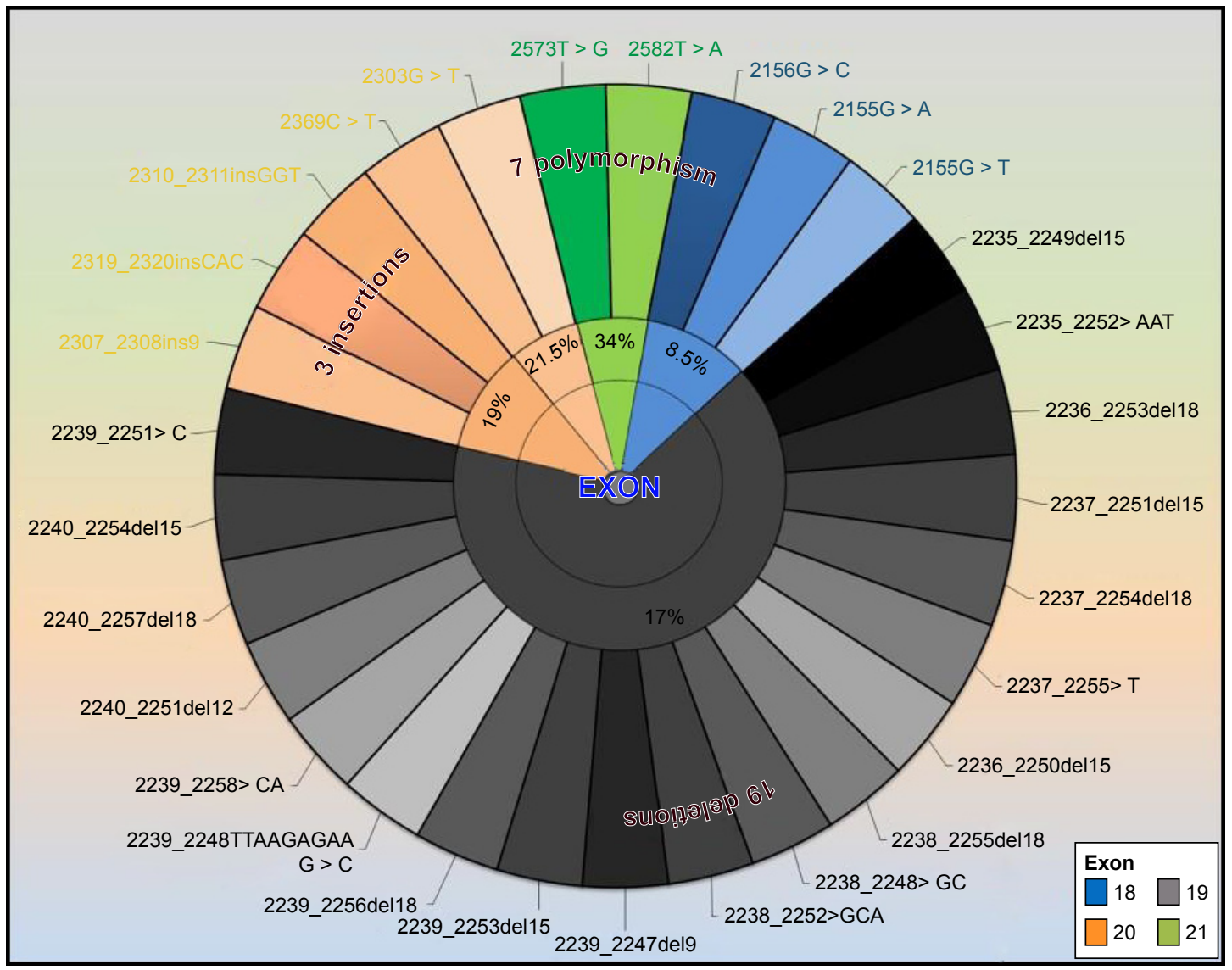

Figure I The somatic mutations of EGFR detected by Therascreen ${ }^{\circledR}$ EGFR RGQ PCR kit.

Notes: The schematic representation of all 29 mutations detected by the Therascreen EGFR RGQ PCR kit and the frequency detected in the present study. The mutations are color coded based on the respective exons. All somatic mutations on exon 18 are coded in shades of blue; exon 19 mutations are coded in shades of gray; exon 20 mutations are coded in shades of orange; and exon 21 mutations are coded in shades of green.

Abbreviations: EGFR, epidermal growth factor receptor; RGQ, Rotor-Gene Q; PCR, polymerase chain reaction.

to test the proportions across the cohort with variables such as age, gender, smoking status, tumor grade, stage, and prognosis was analyzed by using Statistical Package for the Social Sciences (SPSS) version 18 software (SPSS Inc., Chicago, IL, USA).

\section{Results}

The patient cohort comprised Saudi nationals with a median age of 52 years. The gender ratio skewed toward males $(66 \%)$. The majority of tumors were nasopharyngeal squamous cell carcinoma tumors $(42.5 \%)$, followed by laryngeal tumors $(27.6 \%)$, with the remainder mainly comprising hypopharyngeal, oropharyngeal, and oral cavity. Stage 1 and $2 \mathrm{HNSCC}$ represented $40.5 \%$ of the cancers, whereas stages 3 and 4 represented $59.5 \%$. In the cohort, both grade 3 and grade 2 tumors were represented equally ( $40.5 \%$ each), followed by grade 1 tumors (19\%). Data reflected that $44.7 \%$ of patients whose tumor samples were included in the study were smokers (Table 1).

Twenty-seven patients (57\%) exhibited at least one of the specific somatic mutation in the EGFR-TK domain spanning exons 18-21. Of the total mutations, L861Q (exon 21), exon 20 insertions, and deletions of exon 19 accounted for the majority of the mutations $(21 \%, 19 \%$, and $17 \%$, respectively). The resistant mutation T790M (exon 20)

Table I Patient characteristics

\begin{tabular}{lll}
\hline S No & Parameter & Number (\%) \\
\hline I & Gender \\
& Male & $31(66)$ \\
2 & Female & $16(34)$ \\
3 & Median age (years) & 52 \\
& Grade & \\
& Grade I & $9(19)$ \\
& Grade 2 & $19(40.5)$ \\
4 & Grade 3 & $19(40.5)$ \\
& Stage & $19(40.5)$ \\
& Stage I and 2 tumors & $28(59.5)$ \\
& Stage 3 and 4 tumors & $21(44.7)$ \\
& Smoking status & $26(55.3)$ \\
& Smokers & Saudi \\
\hline
\end{tabular}


Table 2 Effect of parameters on EGFR mutation

\begin{tabular}{llll}
\hline Parameter & Mutation (n) & No mutation (n) & P-value \\
\hline Grade I & 2 & 7 & \\
Grade 2 & 12 & 7 & 0.103 \\
Grade 3 & 13 & 6 & 0.041 \\
Grade 2 and 3 & 25 & 13 & 0.026 \\
Stage I and 2 & 7 & 12 & \\
Stage 3 and 4 & 20 & 8 & 0.034 \\
Male & 20 & 11 & \\
Female & 7 & 9 & 0.22 \\
Smoker & 14 & 7 & 0.374 \\
Nonsmoker & 13 & 13 & \\
Good prognosis & 7 & 8 & 0.355 \\
Bad prognosis & 20 & 12 & $0.56 \mathrm{I}$ \\
$\geq 50$ years & 15 & 13 & \\
$<50$ years & 12 & 7 & \\
\hline
\end{tabular}

Abbreviation: EGFR, epidermal growth factor receptor.

and $\mathrm{G} 719 \mathrm{~A} / \mathrm{S} / \mathrm{C}$ (exon 18) were the least observed (8.5\%). Grade 3 tumors had a statistically significant higher rate of mutations compared with low-grade tumors $(P=0.041)$ (Table 2). Similarly, advanced stage tumors were correlated with a high rate of mutation status $(P=0.034)$. Smoking status, gender, and age did not yield any significant correlation with the mutation status.

Furthermore, each specific mutation was compared with specific categories, namely, gender, age ( $<50$ and $>50$ years), smoking status, and prognosis (Table 3 ). The male population had a significantly higher mutation rate of exon 20 insertions $(P=0.019)$. Patients aged $<50$ years had more exon 19 deletions compared with those aged $>50$ years $(P=0.047)$.

\section{Discussion}

The overexpression of EGFR is observed in several malignancies, such as NSCLC, renal cancer, colon cancer, breast cancer, ovarian cancer, and HNSCC. The overexpression of this protein is correlated with a decreased occurrence of disease-free survival. ${ }^{18-23}$ Monoclonal antibodies block the ligand-binding region of EGFR and reduce the TK activation. ${ }^{24,25}$ Currently, the FDA-approved anti-EGFR monoclonal antibodies are cetuximab and panitumumab, with the former for HNSCC and both for colorectal cancer. ${ }^{16}$ Small molecule TKIs bind to the intracellular catalytic domain of the EGFR and inhibit their autophosphorylation and downstream signaling. ${ }^{26}$

Preliminary studies on TKIs such as gefitinib and erlotinib established biological and clinical activity in limited phenotypic and genotypic subclass of lung cancers. ${ }^{27}$ Further exploration revealed optimum response observed in patients who have TK domain mutations. Those mutations are exon 18 (G719X), exon 19 deletions, and exon 21 (L858R) mutations ${ }^{28}$ The acquired resistance was observed in patients having T790M mutation at exon $20 .{ }^{29}$ Recent studies and clinical trials in NSCLC indicate that patients having EGFR mutations show a promising response to the TKIs. Therefore, the study of EGFR mutations in various cancers has gained a lot of importance.

In HNSCC, EGFR mutation frequency differed in ethnic populations, ranging from $7 \%$ in Japanese population, ${ }^{30} 7.3 \%$ in Asian population, ${ }^{31} 15.7 \%$ in Korean population, ${ }^{32}$ and $15.8 \%$ in Greek population. ${ }^{33}$ The highest mutation frequency was $81.39 \%$ in southern Indian population. ${ }^{34}$ No mutations were observed in Belgium ${ }^{16}$ and Spanish $^{35}$ populations. Novel mutations were identified in Japanese and southern Indian populations. ${ }^{30,34}$ The present study observed a frequency of $57 \%$ EGFR mutation among the Saudi population. This EGFR polymorphic variation in HNSCC is ethnically specific, with varying prevalence in different populations. ${ }^{36}$ The variation may also be due to the method of EGFR mutation detection used, which may include Sanger sequencing, hybridization, immunohistochemistry, and real-time PCR. Each assay varies in its sensitivity and specificity. The present study used the Therascreen EGFR RGQ PCR kit for the detection of specific somatic mutations in the EGFR oncogene. This method detects mutation as low as $0.5 \%$ in the background of wild-type DNA.

The major etiological factors for HNSCC are smoking and alcohol consumption, which is why men are at a higher risk than females. ${ }^{30}$ Our study cohort is in line with this, as $66 \%$ of the patients were males and $58 \%$ of the male patient group were smokers compared with $18.75 \%$ in female patients. It is known that the higher-grade HNSCC tumors are associated with a higher number of mutations. ${ }^{17}$ This has also been confirmed by the present study, where a higher number of mutations were observed in high pathological grade tumors $(P=0.026)$.

Molecular studies on HNSCC cohorts revealed that $6.9 \%{ }^{37}$ and $10.5 \%{ }^{30}$ of the patients had a deletion in exon 19 and that the former cohort exhibited a poor prognosis when treated with cetuximab and radiotherapy. Hama et al reported that patients with exon 19 deletions and exon 21 point mutations who had been treated with gefitinib had longer progression and survival times (7.7 vs 2.2 months and 11.6 vs 4.6 months, respectively) when compared with patients who had wild-type EGFR mutation. In the present study, $17 \%$ of patients exhibited a deletion in exon 19, and it was observed that this mutation had a higher prevalence in younger patients $(P=0.047)$ and also that exon 20 insertions 


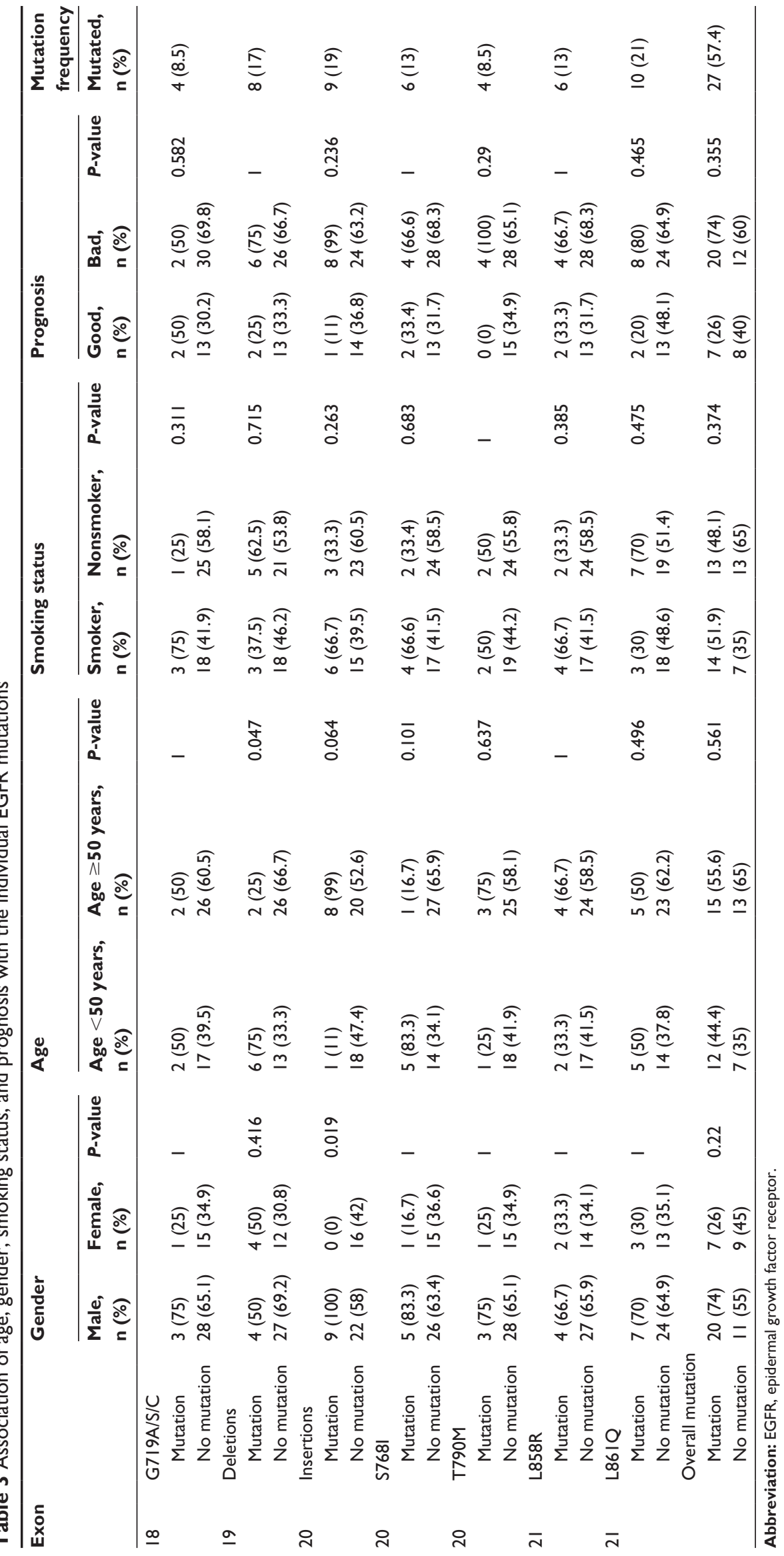


in $19 \%$ of the study cohort and all the insertions in exon 20 were only observed in male patients $(P=0.019)$.

The frequency of exon 18 mutation in our population was $8.5 \%$ compared with that found in Indian population (58\%). ${ }^{34}$ The T790M mutation in exon 20, which is resistant to TKI therapy, was observed in four patients in the present cohort. The present study seems to be the first study reporting the T790M mutation in a HNSCC cohort. Based on the above data, the high frequency of exon 19 deletions and low frequency of T790M resistant mutation indicate that TKIs may be used as an effective treatment strategy. The coexistence of several mutations in the EGFR gene may shed some light on the HNSCC prognosis.

\section{Conclusion}

The higher frequency of EGFR-TK domain mutations together with the presence of the T790M mutation suggests that identification of these mutations might streamline the therapy and provide a better prognosis in HNSCC cases.

\section{Acknowledgments}

The current research was supported by The Deanship of Scientific Research, University of Dammam, Dammam (Grant No: 2014064). The authors would like to thank $\mathrm{Mr}$ Geoffrey James Tam Moro and Mr Florentino Jr Mata for their technical support.

\section{Disclosure}

The authors report no conflicts of interest in this work.

\section{References}

1. Siegel R, Naishadham D, Jemal A. Cancer statistics, 2012. CA Cancer J Clin. 2012;62(1):10-29.

2. Agrawal N, Frederick MJ, Pickering CR, et al. Exome sequencing of head and neck squamous cell carcinoma reveals inactivating mutations in NOTCH1. Science. 2011;333(6046):1154-1157.

3. Stransky N, Egloff AM, Tward AD, et al. The mutational landscape of head and neck squamous cell carcinoma. Science. 2011;333(6046): $1157-1160$

4. Leemans CR, Braakhuis BJ, Brakenhoff RH. The molecular biology of head and neck cancer. Nat Rev Cancer. 2011;11(1):9-22.

5. Yewale C, Baradia D, Vhora I, Patil S, Misra A. Epidermal growth factor receptor targeting in cancer: a review of trends and strategies. Biomaterials. 2013;34(34):8690-8707.

6. Mitsudomi T, Yatabe Y. Epidermal growth factor receptor in relation to tumor development: EGFR gene and cancer. FEBS J. 2010;277(2): 301-308.

7. Hirsch FR, Varella-Garcia M, Cappuzzo F. Predictive value of egfr and her 2 overexpression in advanced non-small-cell lung cancer. Oncogene. 2009;28(Suppl 1):32-37.

8. Franovic A, Gunaratnam L, Smith K, Robert I, Patten D, Lee S. Translational up-regulation of the EGFR by tumor hypoxia provides a nonmutational explanation for its overexpression in human cancer. Proc Natl Acad Sci U S A. 2007;104(32):13092-13097.
9. Zaczek A, Brandt B, Bielawski KP. The diverse signaling network of EGFR, HER2, HER3 and HER4 tyrosine kinase receptors and the consequences for therapeutic approaches. Histol Histopathol. 2005;20(3): 1005-1015.

10. Olayioye MA, Neve RM, Lane HA, Hynes NE. The ErbB signaling network: receptor heterodimerization in development and cancer. EMBO J. 2000;19(13):3159-3167.

11. Han CB, Ma JT, Li F, Zou HW. Molecular markers for the prediction of anti-EGFR monoclonal antibody treatment efficacy in metastatic colorectal cancer. J Cancer Ther. 2011;2:675-682.

12. Baba Y, Fujii M, Tokumaru Y, Kato Y. Present and future of EGFR inhibitors for head and neck squamous cell cancer. J Oncol. 2012;2012: 986725.

13. Sahoo R, Harini VV, Babu VC, et al. Screening for EGFR mutations in lung cancer, a report from India. Lung Cancer. 2011;73(3):316-319.

14. Wykosky J, Mukasa A, Furnari F, Cavenee WK. Escape from targeted inhibition: the dark side of kinase inhibitor therapy. Cell Cycle. 2010; 9(9):1661-1662.

15. Greulich H, Chen TH, Feng W, et al. Oncogenic transformation by inhibitor-sensitive and -resistant EGFR mutants. PLoS Med. 2005;2(11):e313.

16. Boeckx C, Weyn C, Vanden Bempt I, et al. Mutation analysis of genes in the EGFR pathway in head and neck cancer patients: implications for anti-EGFR treatment response. BMC Res Notes. 2014;7:337.

17. Al-Amri AM, Vatte C, Cyrus C, et al. Novel mutations of PIK3CA gene in head and neck squamous cell carcinoma. Cancer Biomark. 2016; 16(3):377-383.

18. Mellon K, Wright C, Kelly P, Horne CH, Neal DE. Long-term outcome related to epidermal growth factor receptor status in bladder cancer. J Urol. 1995;153(3 Pt 2):919-925.

19. Tanner M, Hollmén M, Junttila TT, et al. Amplification of HER-2 in gastric carcinoma: association with Topoisomerase IIalpha gene amplification, intestinal type, poor prognosis and sensitivity to trastuzumab. Ann Oncol. 2005;16(2):273-278.

20. Lo HW, Hsu SC, Hung MC. EGFR signaling pathway in breast cancers: from traditional signal transduction to direct nuclear translocalization. Breast Cancer Res Treat. 2006;95(3):211-218.

21. Araújo A, Ribeiro R, Azevedo I, et al. Genetic polymorphisms of the epidermal growth factor and related receptor in non-small cell lung cancer - a review of the literature. Oncologist. 2007;12(2):201-210.

22. Farnebo L, Jedlinski A, Ansell A, et al. Proteins and single nucleotide polymorphisms involved in apoptosis, growth control, and DNA repair predict cisplatin sensitivity in head and neck cancer cell lines. Int $\mathrm{J} \mathrm{Mol}$ Med. 2009;24(4):549-556.

23. Hsieh YY, Tzeng CH, Chen MH, Chen PM, Wang WS. Epidermal growth factor receptor R521K polymorphism shows favorable outcomes in KRAS wild-type colorectal cancer patients treated with cetuximabbased chemotherapy. Cancer Sci. 2012;103(4):791-796.

24. Garrett TP, McKern NM, Lou M, et al. Crystal structure of a truncated epidermal growth factor receptor extracellular domain bound to transforming growth factor alpha. Cell. 2002;110(6):763-773.

25. Ogiso H, Ishitani R, Nureki O, et al. Crystal structure of the complex of human epidermal growth factor and receptor extracellular domains. Cell. 2002;110(6):775-787.

26. Azemar M, Schmidt M, Arlt F, et al. Recombinant antibody toxins specific for ErbB2 and EGF receptor inhibit the in vitro growth of human head and neck cancer cells and cause rapid tumor regression in vivo. Int J Cancer. 2000;86(2):269-275.

27. Fukuoka M, Yano S, Giaccone G, et al. Multi-institutional randomized phase II trial of gefitinib for previously treated patients with advanced non-small-cell lung cancer (the IDEAL 1 trial). J Clin Oncol. 2003;21(12):2237-2246.

28. Lynch TJ, Bell DW, Sordella R, et al. Activating mutations in the epidermal growth factor receptor underlying responsiveness of non-small-cell lung cancer to gefitinib. $N$ Engl J Med. 2004;350(21):2129-2139.

29. Pao W, Miller VA, Politi KA, et al. Acquired resistance of lung adenocarcinomas to gefitinib or erlotinib is associated with a second mutation in the EGFR kinase domain. PLoS Med. 2005;2(3):e73. 
30. Hama T, Yuza Y, Saito Y, et al. Prognostic significance of epidermal growth factor receptor phosphorylation and mutation in head and neck squamous cell carcinoma. Oncologist. 2009;14(9):900-908.

31. Lee JW, Soung YH, Kim SY, et al. Somatic mutations of EGFR gene in squamous cell carcinoma of the head and neck. Clin Cancer Res. 2005;11(8):2879-2882.

32. Na II, Kang HJ, Cho SY, et al. EGFR mutations and human papillomavirus in squamous cell carcinoma of tongue and tonsil. Eur J Cancer. 2007;43(3):520-526.

33. Murray S, Bobos M, Angouridakis N, et al. Screening for EGFR mutations in patients with head and neck cancer treated with gefitinib on a compassionate-use program: A Hellenic Cooperative Oncology Group Study. J Oncol. 2010;2010:709678.

34. Nagalakshmi K, Jamil K, Pingali U, Reddy MV, Attili S. Epidermal growth factor receptor (EGFR) mutations as biomarker for head and neck squamous cell carcinomas (HNSCC). Biomarkers. 2014;19(3): 198-206.
35. Lemos-González Y, Páez de la Cadena M, Rodríguez-Berrocal FJ, Rodríguez-Piñeiro AM, Pallas E, Valverde D. Absence of activating mutations in the EGFR kinase domain in Spanish head and neck cancer patients. Tumour Biol. 2007;28(5):273-279.

36. Loeffler-Ragg J, Witsch-Baumgartner M, Tzankov A, et al. Low incidence of mutations in EGFR kinase domain in Caucasian patients with head and neck squamous cell carcinoma. Eur J Cancer. 2006;42(1): 109-111.

37. Smilek P, Neuwirthova J, Jarkovsky J, et al. Epidermal growth factor receptor (EGFR) expression and mutations in the EGFR signaling pathway in correlation with anti-EGFR therapy in head and neck squamous cell carcinomas. Neoplasma. 2012;59(5):508-515.

\section{Publish your work in this journal}

OncoTargets and Therapy is an international, peer-reviewed, open access journal focusing on the pathological basis of all cancers, potential targets for therapy and treatment protocols employed to improve the management of cancer patients. The journal also focuses on the impact of management programs and new therapeutic agents and protocols on

\section{Dovepress}

patient perspectives such as quality of life, adherence and satisfaction. The manuscript management system is completely online and includes a very quick and fair peer-review system, which is all easy to use. Visit http://www.dovepress.com/testimonials.php to read real quotes from published authors.

Submit your manuscript here: http://www.dovepress.com/oncotargets-and-therapy-journal 